\title{
A comparative clinical study on efficacy of terbinafine and griseofulvin in patients with tinea corporis
}

\author{
G. Muthu Kavitha ${ }^{1}$, M. Shanthi ${ }^{2}$, M. S. Ahil ${ }^{2}$ \\ ${ }^{1}$ Department of Pharmacology, Government Theni Medical College, Theni, Tamil Nadu, India \\ ${ }^{2}$ Department of Pharmacology, Madurai Medical College, Madurai, Tamil Nadu, India
}

Received: 06 November 2019

Revised: 13 December 2019

Accepted: 16 December 2019

\section{*Correspondence:}

Dr. G. Muthu Kavitha,

Email: maheshwari200789@gmail.com

Copyright: $(\odot$ the author(s), publisher and licensee Medip Academy. This is an open-access article distributed under the terms of the Creative Commons Attribution Non-Commercial License, which permits unrestricted non-commercial use, distribution, and reproduction in any medium, provided the original work is properly cited.

\begin{abstract}
Background: The objective of the present study was to compare the efficacy of terbinafine and griseofulvin in patients with tinea corporis in a tertiary care hospital, Madurai.

Methods: About 60 patients are selected from the outpatient department of Dermatology according to inclusion and exclusion criteria. They were divided into 2 groups of 30 patients each. Group 1 received tab. terbinafine $250 \mathrm{mg}$ OD and group 2 received $250 \mathrm{mg} \mathrm{BD}$ for 4 weeks. All patients were investigated at baseline, end of $2^{\text {nd }}$ week and at end of 4 weeks. Effectiveness of both the drugs were determined by achieving clinical as well as mycological cure. The results were recorded, tabulated and analysed using student's test.

Results: Patients in group 1 showed higher clinical and mycological cure rate when compared with group 2.

Conclusions: Oral terbinafine is the effective antifungal agent in the treatment of extensive tinea corporis infection.
\end{abstract}

Keywords: Terbinafine, Griseofulvin, Tinea corporis

\section{INTRODUCTION}

Fungi are a large and diverse group of organisms that exist as saprophytes, parasites or commensals. ${ }^{1}$ Because of their ubiquitous nature, fungi can colonize any environment and they play an important role in the decomposition and recycling of organic matter. ${ }^{2}$ The incidence of serious systemic fungal infections is in an increasing trend since 1970s. Fungi can cause harmful effects by producing mycotoxins, by evoking allergic reactions, or by direct tissue invasion.

Various types of 'tinea' infections are caused by Trichophyton, Microsporum or Epidermophyton. Tinea corporis is defined as dermatophytosis of the glabrous skin with the exclusion of the palms, soles and groins. Tinea corporis has a worldwide distribution, but a higher prevalence is reported from tropical and subtropical areas. The prevalence of tinea corporis is high (41\%) among all fungal infections in Southern region of Tamil Nadu. The treatment of dermatophytosis usually involves the use of one of several well tried topical preparations. Mild and isolated lesions may respond to topical antifungal agents like clotrimazole, miconazole, econazole, undecylenic acid and Whitfield ointment etc. When the lesion is widespread or extensive, along with topical antifungal preparations, systemic therapy can be used. Since 1956, Amphotericin B was the only efficacious antifungal drug available for systemic use for many years. Then, griseofulvin which was first isolated from Penicillium griseofulvum, in 1939 by Oxford and colleague came to the market, but its efficacy asan oral antifungal agent was first shown in 1958. Then the nontoxic azole drugs and the echinocandins were introduced and they have revolutionized pharmacotherapy of fungal 
infection in the last several decades. They provide more targeted, less toxic therapy than older agents. ${ }^{3}$

Newer antifungal agent such as terbinafine is an allylamine derivative. It is highly lipophilic and keratinophilic in nature. It is usually effective against dermatophytes but less effective in Candida species. Squalene epoxidase is inhibited by terbinafine that causes fungal cell death (fungicidal). ${ }^{4}$ Both topical and oral forms are available for therapeutic purpose. On oral administration, it is rapidly taken up into the stratum corneum. Rapid and long lasting remissions with much lower frequency of relapse in tinea corporis is produced by terbinafine when compared with griseofulvin. Patients with extensive and recurrent tinea corporis, maybe the major source of infection in their society. ${ }^{5}$ It is very difficult to eradicate dermatophytosis completely with topical agents alone. So, to prevent the spread of infection, prompt treatment with oral antifungal agents which are more efficacious has to be used. Hence, this study is undertaken to compare the efficacy and safety of terbinafine and griseofulvin in patients with tinea corporis in the tertiary care hospital, Madurai.

\section{Objective}

The objective of the present study was to compare the efficacy of terbinafine and griseofulvin in tinea corporis patients in the tertiary care hospital, Madurai.

\section{METHODS}

The study was carried out in the Department of Dermatology, Biochemistry, Microbiology Government Rajaji Hospital, Madurai, from April 2014 to March 2015 after obtaining clearance from institutional ethical committee Ref number (6506/E1/5/2014), Government Rajaji Hospital, Madurai. A single center open label prospective comparative clinical study carried out in 60 patients. Group I (30 patients) received oral tab. terbinafine $250 \mathrm{mg}$ /day for 4 week and Group II (30 patients) received oral tab. griseofulvin $10 \mathrm{mg} / \mathrm{kg} / \mathrm{day}$ for 4 weeks.

\section{Inclusion criteria}

Age ranged from 18 to 45 years, both male and female, new patients with fungal infection involving body region $(>10 \mathrm{~cm}$ in size), patients with potassium hydroxide $(\mathrm{KOH})$ preparation positive for fungal elements on direct microscopy were included in the study.

\section{Exclusion criteria}

Patients with negative $\mathrm{KOH}$ preparation for fungal elements, patients treated with topical antifungal agents within past 2 weeks, patients treated with systemic antifungal agents within past 30 days, patients with elevated liver enzymes and $\mathrm{H} / \mathrm{O}$ active liver disease, patients with diabetes mellitus, HIV/AIDS, patients on immunosuppressant drugs, patients taking oral corticosteroids, pregnant and lactating women, children, patients with history of hypersensitivity to any other drugs were excluded from the study.

After selecting the patient, a detailed clinical record was prepared including age, sex, address, occupation, family history, duration of the disease, size and extent of lesion, history of pervious drug intake. An enquiry about associated co morbidities like diabetes mellitus HIV/AIDS, malignancies, and immunosuppressive therapy were recorded.

Then all the patients were subjected for local and systemic examinations in detail. After that, all patients were tested for necessary investigations which include complete hemogram, liver function test, renal function test and fungal test-KOH mount. Diagnosis was based on clinical features, $\mathrm{KOH}$ preparation on direct microscopy, and culture on Sabouraud's agar.

\section{Follow up and evaluation}

Patients were followed at the end of every week. Skin scrapings were taken for mycology at baseline and at the end of 2 nd and 4th weeks. The efficacy of the drugs were assessed by clinical cure, mycological cure. ${ }^{6}$ Every week all the patients in both the groups were examined for mycological cure microscopic examination of $\mathrm{KOH}$ mount of the scrapings. The clinical cure was assessed by clinical response rates. ${ }^{6}$ The three target symptoms assessed were scaling, erythema and pruritus.

The total clinical evaluation was rated as,

- A: Healed (absence of signs and symptoms),

- B: Markedly improved (>50\% clinical improvement),

- C: Considerable residual lesions $(<50 \%$ clinical improvement),

- D: No change,

- E: Worse.

\section{Statistical method}

Data analysis was done with the help of computer by using SPSS software and Sigma Stat 3.5 version (2012). Using this software, percentage, mean, standard deviation and ' $p$ ' value were calculated through Student's ' $t$ ' test for all the parameters. $\mathrm{P}$ value of $<0.05$ was taken as significant.

\section{RESULTS}

The mean fungal size 2 weeks after treatment in griseofulvin group was $90.33 \mathrm{~cm}$ whereas in terbinafine group it was only 34.47 indicating greater reduction which was statistically highly significant $(\mathrm{p}<0.0000001)$. In same way, terbinafine again showed greater reduction in fungal size when compared to griseofulvin 4 weeks 
after treatment which was also statistically significant

$(\mathrm{p}<0.00002)$ (Table 1).

Table 1: Distribution of mean size of fungal lesion in terbinafine and griseofulvin.

\begin{tabular}{|lllllllllll|}
\hline & $\begin{array}{l}\text { Group 1 } \\
\text { Mean fungal } \\
\text { size (mm) }\end{array}$ & SD & Mean & SD & T value & $\begin{array}{l}\text { Degr } \\
\text { ee of } \\
\text { freed } \\
\text { om }\end{array}$ & P value & $\begin{array}{l}\text { Signif- } \\
\text { icance of } \\
\text { reduc- } \\
\text { tion }\end{array}$ \\
\hline Baseline & 137.8 & 26.13 & 142.63 & 20.44 & -0.792 & 58 & 0.428 & NS & 3.38 \\
\hline $\begin{array}{l}\text { 2 weeks after } \\
\text { treatment }\end{array}$ & 34.47 & 12.34 & 90.33 & 21.75 & -12.235 & 58 & $<0.0000001$ & Sig & 61.84 \\
\hline $\begin{array}{l}\text { 4 weeks after } \\
\text { treatment }\end{array}$ & 1.9 & 0.845 & 17.2 & 18.22 & -4.59 & 58 & $<0.00002$ & Sig & 88.96 \\
\hline
\end{tabular}

\section{Mycological cure rate}

In group 1 , out of 30 patients, 10 showed negative $\mathrm{KOH}$ wet mount examination at the end of $2^{\text {nd }}$ week and the remaining 20 were also became negative for $\mathrm{KOH}$ wet mount examination at the end of $4^{\text {th }}$ week which reflects the high efficacy of terbinafine on tinea corpor is infection when compared to griseofulvin (Table 2). $\mathrm{KOH}$ wet mount of Group1 and Group 2.

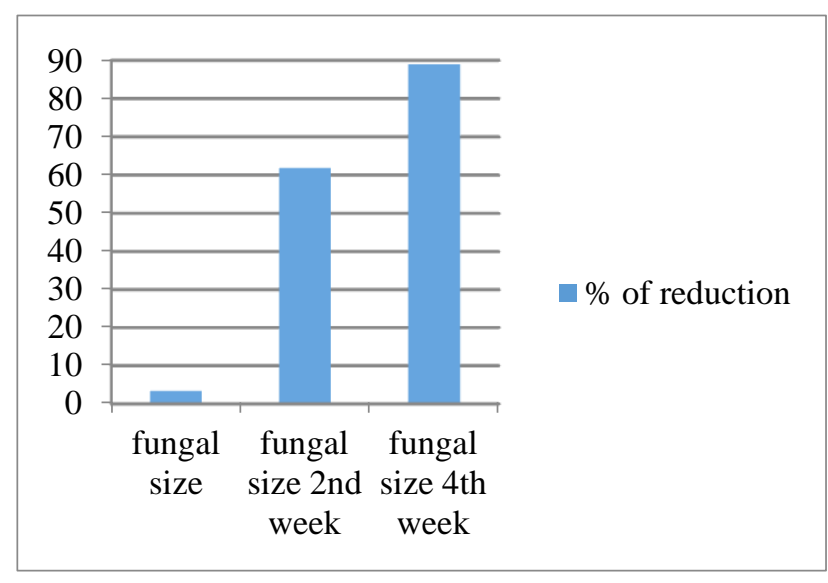

Figure 1: Fungal size percentage of reduction.

Table 2: Mycological cure rate.

\begin{tabular}{|lll|}
\hline KOH & Group 1 & Group 2 \\
\hline Base line & 30 & 30 \\
\hline 2nd week & 20 & 30 \\
\hline 4th week & 0 & 13 \\
\hline
\end{tabular}

Group 1 showed increased cure rate score compared to group 2 (Table 3 ).

Table 3: Clinical cure rate.

\begin{tabular}{|llll|}
\hline Score & Description & Group 1 & Group 2 \\
\hline A & Healed & 28 & 15 \\
\hline B & $>50 \%$ improvement & 2 & 7 \\
\hline C & $<50 \%$ improvement & 0 & 8 \\
\hline D & No change & 0 & 0 \\
\hline E & Worse & 0 & 0 \\
\hline
\end{tabular}

\section{DISCUSSION}

Superficial fungal infections caused by dermatophytes are clinically classified on the basis of the location of the lesions on the body. In tropical and sub-tropical countries including India, tinea infection is one of the important public health problem where the growth of fungi is promoted by heat and moisture. ${ }^{7}$ Since most of the tinea infections seen in body, face and limbs are acquired from the zoophilic species, the persons who are in close contact with animals such as cattles, cats and dogs are also more prone to develop dermatophytosis. This pattern is also observed in this study.

Health education to create awareness is one of the essential tool in the prevention of dermatophytosis. Regarding treatment of patients with tinea corporis infection, topical therapy is preferable when smaller areas are affected. Extensive lesions due to anthropophilic dermatophyte species, invasive lesions, relapse/recurrence of the tinea infection, chronic dry manifestations of tinea corporis caused by $T$. rubrum needs systemic therapy. ${ }^{8}$ Oral griseofulvin and ketoconazole have been used to treat extensive lesions for many years. But due to the development of side effects like hepatotoxicity and androgen abnormalities the use of ketoconazole is restricted nowadays.

The first orally active, systemic antifungal agent used in the treatment of dermatophytosis was griseofulvin. It is only fungistatic. The bioavailability of griseofulvin is poor. It should be taken with high-fat meals and as ultrafine crystalline preparations to enhance adequate absorption from the gastrointestinal tract. Griseofulvin induces hepatic cytochrome $\mathrm{P} 450$ activity. The rate of metabolism of a number of drugs is increased by griseofulvin. Relapses are more common with griseofulvin. Multiple doses should be taken daily. Treatment should be continued until the disappearance of the fungal lesion. One third of patients do not respond to treatment with griseofulvin due to the development of resistant mutants. ${ }^{9}$ The overall compliance of the patient will be less.

Terbinafine is a fungicidal agent active against most of the dermatophytes. Single daily dose of $250 \mathrm{mg}$ for $2-4$ 
weeks is highly curative and obtained high compliance among all the patients when compared with multiple doses of griseofulvin. Food does not cause any change in absorption. The relapse/recurrence are very much minimal with this drug when compared with other agents. There are no serious drug interactions.

Our present study has observed that out of 60 patients diagnosed for dermatophytosis, $23(38.3 \%)$ were male and $37(61.6 \%)$ were female with $\mathrm{M}$ : $\mathrm{F}$ ratio of $0.62: 1$. We have also observed that $88 \%$ of tinea corporis occurred during the age of 26 to 45 .

In our present study, the most common causative organism isolated after culture report was T. rubrum, 34 cases $(56.6 \%)$ followed by $T$. mentagrophyte, 14 cases (23.3\%) T. tonsurans, 8 cases (13.3\%), M. canis, 4 cases $(6.6 \%)$ and. In a study conducted by Venkatesan et al, the major causative organism isolated was $T$. rubrum (69.6\%), followed by $T$. mentagrophyte $(28.2 \%)$ and $M$. gypseum $(2.2 \%)$ from tinea corporis patients. ${ }^{10}$ The mean clinical score based on signs and symptoms at baseline in terbinafine group was 2.6 and in griseofulvin group was 2.64. There was significant reduction in the clinical score at the end of 4 th week in terbinafine group (0.1) when compared to griseofulvin group (0.9). The clinical response rate of Group 1 at 4th week was $93.3 \%$ whereas, of Group 2 was $50 \%$.

The mycological cure in terbinafine treated patients in group1 was $100 \%$ and griseofulvin treated patients in Group 2 was $66.6 \%$ at the end of 4 th week in the study population. This is comparable with the study conducted by Voravutinon. ${ }^{11}$ The reduction in size of the fungal lesion was $88.2 \%$ in Group 1 patients when compared with Group 2 where it was $65.3 \%$.

In the present study, terbinafine has high efficacy rate in curing extensive tinea corporis with clinical cure rate of 93.3\% and mycological cure rate of $100 \%$. On follow up, there was no relapse found in Group 1 (terbinafine) patients. In Group 2 (griseofulvin), the clinical cure rate is $50 \%$, and the mycological cure rate is $56.6 \%$.

Terbinafine is most commonly used in the treatment of dermatophytosis nowadays. It requires shorter duration of therapy and is more effective than griseofulvin. ${ }^{12}$ Patient's compliance is also good with terbinafine due to a short duration of therapy such as 2 to 4 weeks. This is very much useful in the management of chronic and recurrent infections and also in source reduction on community basis.

Though the cost of terbinafine is more than griseofulvin, due to short duration of therapy, better compliance and $100 \%$ mycological cure, we can reduce reinfection and also the spread of disease. ${ }^{13}$ So, the overall burden of the disease will be less when compared with griseofulvin.
Hence, from this study we can infer that terbinafine seems to be more effective than griseofulvin as it provides better clinical as well as mycological cure within a short period and with no relapse in patients with tinea corporis.

\section{CONCLUSION}

When compared with griseofulvin, oral terbinafine provides clinical as well as mycological cure with short course of treatment. And there is no evidence of relapse in the treatment of tinea corporis infection. Since the present study involved a small sample size with one particular tinea infection for a short duration, further more studies are needed with large samples at multicentric levels for long duration in all the variety of tinea infections.

\section{ACKNOWLEDGEMENTS}

I am greatly indebted to, Dr. R. Parameswari M.D., Director and Professor Institute of Pharmacology, Madurai medical college, Madurai for her remarkable guidance, encouragement and selfless support which enabled me to pursue the work with perseverance. I am extremely thankful to my guide for her valuable suggestions and critical review at every stage for the successful completion of this study. I record my sincere and heartfelt thanks to Assistant Professor of Pharmacology, Madurai Medical College, Madurai for her untiring support, continuous suggestions and enduring encouragement throughout the study.

\section{Funding: No funding sources \\ Conflict of interest: None declared}

Ethical approval: The study was approved by the Institutional Ethics Committee

\section{REFERENCES}

1. Kanwar AJ, Dipankar De. Superficial Fungal Infections. In: Valia RG, Valia AR, eds. Textbook of Dermatology, 3rd ed. Mumbai: Bhalani Publishing House; 2008: 252-290.

2. Hay RJ. Ashbee HR. Mycology. In: Burns T, Breathnach S, Cox N, Griffiths C, eds. Rook's Textbook of Dermatology. 8th ed. London: WileyBlackwell Publication; 2011;2(36):18-50.

3. Bennett JE. Antifungal agents. In: Brunton LL, Chabner BA, Knollmann BC, eds. Goodman and Gilman's The Pharmacological basis of therapeutics. 12th ed. New York: McGraw Hill; 2011: 1571-1592.

4. Rang HP, Dale MM, Ritter JM, Flower RJ, Henderson G. Antifungal agents. Rang and Dale's Pharmacology. 7th ed. Toronto: Elsevier; 2012: 649653.

5. MacDonald E, Head ES. Introduction to fungal infections. In: Demis DJ, ed. Clinical dermatology. Philadelphia: JB Lippincott; 1989: section 17.1. 
6. Hay RJ, Roberts SOB, Mackenzie DWR. Mycology. In: Champion RH, Burton JL, Ebling FJG, eds. Textbook of dermatology. Oxford: Blackwell Scientific Publications; 1992: 1128.

7. Jyothi N, Judith J, Nirmaladevi P. A Study on cutaneous infections among adults at the dermatology outpatient department in a rural tertiary care center. Tirunelveli J Med Sci. 2013;5:112-3.

8. Gupta AK. Systemic antifungal agents. In: Wolverton SE, eds. Comprehensive Dermatologic Drug Therapy, 3rd ed. USA: Elsevier publication; 2013: 98-119.

9. Chander J. Dermaptophytoses. In: Chander J (ed). Text book of Medical Mycology. $3^{\text {rd }}$ edition. New Delhi: Mehta Offset Pvt Ltd; 2009: 122-142.

10. Venkatesan G, Singh AJAR, Murugesan AG, Janaki C, Shankar GS. Trichophyton rubrum- the predominant etiological agent in human dermatophytoses in Chennai, India. Afr J Microbiol. 2007;5:9-12.

11. Voravutinon V. Oral treatment of tineacorporis and tineacruris with terbinafine and griseofulvin: a randomized double blind comparative study. J Med Assoc Thai. 1993;76:388-93.

12. Beller M, Gessner BD. An outbreak of tinea corporis gladiatorum on a high school wrestling team. J Am Acad Dermatol. 1994;31:197-201.

13. Padhye AA, Summerbell RC. The Dermatophytes. In: Merz WG, Hay RJ, eds. Topley Wilson's Medical Mycology, 10th ed. London: ASM Press; 2005: 220238.

Cite this article as: Kavitha GM, Shanthi M, Ahil MS. A comparative clinical study on efficacy of terbinafine and griseofulvin in patients with tinea corporis. Int J Basic Clin Pharmacol 2020;9:181-5. 